\title{
A Retrospective Study: Epidemiology, Onset, and Duration of Erythema Nodosum Leprosum in Surabaya, Indonesia
}

\author{
Cindy Fransisca ${ }^{1}$, Iskandar Zulkarnain ${ }^{1}$, Evy Ervianti', Damayanti ${ }^{1}$, Maylita Sari', \\ Budiono $^{2}$, Cita Rosita Sigit Prakoeswa ${ }^{1}$, Medhi Denisa Alinda ${ }^{1}$, Bagus Haryo \\ Kusumaputra ${ }^{1}$, Muhammad Yulianto Listiawan ${ }^{1}$ \\ ${ }^{1}$ Department of Dermatology and Venereology, Faculty of Medicine, Universitas Airlangga, Dr. \\ Soetomo General Academic Teaching Hospital, Surabaya, Indonesia \\ ${ }^{2}$ Department of Public Health Sciences, Faculty of Medicine, Universitas Airlangga, Surabaya, \\ Indonesia
}

\begin{abstract}
Background: Erythema nodosum leprosum (ENL) has a chronic and recurrent nature which could reduce patient's quality of life in addition to the onset of ENL that occurs before, during, or after multidrug treatment, further emphasizing the importance of regular control and education. Purpose: This study aimed to evaluate the epidemiology, onset, duration, and recurrence of ENL. Methods: Data from medical records were obtained for a 3-year retrospective study of multibacillary leprosy patients at the Leprosy Division of the Dermatology and Venereology Outpatient Department, Dr. Soetomo General Hospital Surabaya, with a minimum of 2-5 years follow-up period. Result: The prevalence of ENL continued to increase almost every year especially in 2017 (32\% in 2015; 32\% in 2016; and 36\% in 2017). ENL most often occurs during the first year of multi-drug therapy (MDT) administration followed by after the release from treatment (RFT) with the latest onset occurring 4 years after RFT. The majority of patients experienced chronic and recurrent reactions with the longest reactions lasting up to 4.5 years (55 months). Conclusion: Knowledge about the onset, duration, and recurrences of ENL are essential, and strict supervision for routine control shall be encouraged to increase the patients' compliance so as to increase their quality of life.
\end{abstract}

Keywords: Erythema nodosum leprosum, epidemiology, onset, duration, recurrent.

Correspondence: Muhammad Yulianto Listiawan, Department of Dermatology and Venereology Faculty of Medicine, Universitas Airlangga, Dr. Soetomo General Academic Hospital, Surabaya, Jl. Mayjen Prof. Dr. Moestopo No. 6-8 Surabaya 60131, Indonesia. Phone: (031) 5501609, e-mail: yuliantowawan@yahoo.com

\section{BACKGROUND}

Erythema nodosum leprosum (ENL) can occur spontaneously or due to leprosy treatment. The reactions can occur before, during, or even years after the completion of treatment or release from treatment (RFT) with multi-drug therapy (MDT). ${ }^{1}$ ENL episodes can develop into a chronic condition with recurrent episodes and can continue for many years. Therefore, it requires long-term therapy which can cause side effects and even comorbidity and mortality. ${ }^{1-3}$

This retrospective study was conducted to determine the incidence of ENL and its distribution in multibacillary type leprosy, the onset of reactions based on MDT administration, duration, and recurrences of ENL. Evaluation of incidence, onset, and duration of reactions is important to improve monitoring and education of possible reactions even years after therapy is completed to promote mandatory routine control. The evaluation of ENL duration is important as the disease has a chronic and recurrent nature which can even continue for years. ${ }^{2,4}$ This study was conducted with the hope of providing better management, education, and monitoring for those diagnosed with ENL and increase doctors' awareness in providing medical services, especially regarding the chronic and recurrent nature of ENL.

\section{METHODS}

This was a descriptive retrospective study. The data were obtained from medical records of new leprosy patients at the Leprosy Division, Dermatology and Venerology Outpatient Department, Dr. Soetomo General Academic Hospital from January 2015 to December 2017 with a follow-up period of 2-5 years. Acute ENL means an episode lasting less than 6 months, and chronic if it lasts for 6 months or longer, including the treatment-free interval in less than 28 days; it can be expressed as a single episode or recurrent if subsequent reactions occurred $\geq 28$ days after the discontinuation of ENL therapy. The descriptive data includes the onset, duration, and recurrence of ENL patients. Ethical clearance was obtained from the Ethical Committee of Dr. Soetomo General Hospital Surabaya with reference number: 


\section{3/LOE/301.4.2/VI/2020}

\section{RESULT}

A total of 385 new patients visited Leprosy Division in January 2015-December 2017. Three hundred thirty two of them were multibacillary (MB) patients, 47 were paucibacillary $(\mathrm{PB})$ patients, and 6 patients were unknown. Out of the 385 patients, 111 (28.8\%) patients developed ENL which included 48 previously treated patients and 63 previously untreated patients.
Three hundred thirty two of new MB leprosy patients came to the Leprosy Division of the Dermatology and Venereology Outpatient Department of Dr. Soetomo General Academic Teaching Hospital Surabaya in $2015-2017$, which was $86.2 \%$ from the total number of new leprosy patients. There were 111 MB leprosy + ENL patients that they yielded $28.8 \%$ of the total number of new leprosy patients and $33.4 \%$ of the total number of MB leprosy patients. The ratio of patients with MB leprosy and MB + ENL was 3:1.

Table 1. Distribution of MB leprosy patients and MB leprosy patients + ENL in Leprosy Division Dr. Soetomo General Academic Teaching Hospital Surabaya Period 2015-2017

\begin{tabular}{lcccc}
\hline \multirow{2}{*}{ Patient } & \multicolumn{3}{c}{ Year } & \multirow{2}{*}{ Total (\%) } \\
\cline { 2 - 4 } & 2015 & 2016 & 2017 & \\
\hline MB Leprosy & $(\%)$ & $(\%)$ & $1 \%)$ & 332 \\
& 124 & 88 & $(36.1)$ & $(86.2)$ \\
MB Leprosy+ENL & $(37.3)$ & $(26.5)$ & 43 & 111 \\
& 40 & 28 & $(38.7)$ & $(28.8)$ \\
Leprosy Division & $(36)$ & $(25.2)$ & 136 & 385 \\
& 148 & 101 & $(35.3)$ & $(100)$ \\
\hline
\end{tabular}

MB: Multibacillary

ENL: Erythema nodosum leprosum

Table 2. The distribution of ENL onset in MB leprosy patients at the Leprosy Division, Dr. Soetomo General Academic Teaching Hospital Surabaya in 2015-2017

\begin{tabular}{lrrrr}
\hline \multicolumn{1}{c}{ MDT Status } & \multicolumn{3}{c}{ Year } & \multicolumn{1}{c}{ Total } \\
& \multicolumn{1}{c}{$2015(\%)$} & $2016(\%)$ & $2017(\%)$ & $18(16.2)$ \\
\cline { 2 - 4 } Before MDT & $7(6.3)$ & $2(1.8)$ & $9(8.1)$ & $33(29.7)$ \\
MDT 1-6 & $15(13.5)$ & $7(6.3)$ & $11(9.9)$ & $11(9.9)$ \\
MDT 7-12 & $2(1.8)$ & $4(3.6)$ & $5(4.5)$ & $0(0.0)$ \\
MDT > 12 & $0(0.0)$ & $0(0.0)$ & $0(0.0)$ & $34(30.6)$ \\
RFT year 1 & $8(7.2)$ & $12(10.8)$ & $14(12.6)$ & $4(3.6)$ \\
RFT year 2 & $1(0.9)$ & $2(1.8)$ & $1(0.9)$ & $2(1.8)$ \\
RFT year 3 & $0(0.0)$ & $1(0.9)$ & $1(0.9)$ & $1(0.9)$ \\
RFT year 4 & $0(0.0)$ & $0(0.0)$ & $1(0.9)$ & $8(7.2)$ \\
No data & $7(6.3)$ & $0(0.0)$ & $43(38.7)$ & $111(100)$ \\
\hline Total & $40(36)$ & $28(25.2)$ &
\end{tabular}

MDT: Multidrug therapy

RFT: Release from treatment

Table 3. The summary distribution of ENL onset in MB leprosy patients at the Leprosy Division, Dr. Soetomo General Academic Teaching Hospital Surabaya in 2015-2017

\begin{tabular}{lrrrr}
\hline \multicolumn{1}{c}{ MDT Status } & \multicolumn{1}{c}{ Year } & \multicolumn{1}{c}{ Total } \\
\cline { 2 - 4 } & \multicolumn{1}{c}{$2015(\%)$} & $2016(\%)$ & $2017(\%)$ & \multicolumn{1}{c}{$(\%)$} \\
\hline Before MDT & $7(6.3)$ & $2(1.8)$ & $9(8.2)$ & $18(16.3)$ \\
MDT $\leq 6$ & $15(13.5)$ & $7(6.3)$ & $11(9.9)$ & $33(29.7)$ \\
MDT $>6$ & $2(1.8)$ & $4(3.6)$ & $5(4.5)$ & $11(9.9)$ \\
RFT & $9(8.1)$ & $15(13.5)$ & $17(15.3)$ & $41(36.9)$ \\
No data & $7(6.3)$ & $0(0.0)$ & $1(0.9)$ & $8(7.2)$ \\
\hline Total & $40(36)$ & $28(25.2)$ & $43(38.8)$ & $111(100)$ \\
\hline
\end{tabular}

MDT: Multidrug therapy

RFT: Release from treatment 
Table 2 and 3 showed that the onset of ENL in MB leprosy patients most often occurred during the first year of MDT, as observed in 44 patients (39.6\%), including 33 patients $(29.7 \%)$ during the first 6 months of MDT, and 11 patients (9.9\%) after 6 months of MDT, followed by 41 patients $(36.9 \%)$ after RFT. The latest onset of reactions occurred 4 years after RFT. There were 8 ENL patients without onset data.

Table 4. The distribution of ENL duration and recurrences in MB leprosy patients at the Leprosy Division Dr. Soetomo General Academic Teaching Hospital Surabaya in 2015-2017

\begin{tabular}{|c|c|c|c|c|c|c|c|}
\hline \multirow[t]{3}{*}{ Duration } & \multicolumn{6}{|c|}{ Year } & \multirow[t]{2}{*}{ Total (\%) } \\
\hline & \multicolumn{2}{|c|}{$2015(\%)$} & \multicolumn{2}{|c|}{$2016(\%)$} & \multicolumn{2}{|c|}{$2017(\%)$} & \\
\hline & Single & Recurrent & Single & Recurrent & Single & Recurrent & \\
\hline \multirow[t]{2}{*}{$<6$ months } & 6 & 0 & 5 & 1 & 13 & 1 & 26 \\
\hline & (5.4) & $(0.0)$ & $(4.5)$ & $(0.9)$ & $(11.7)$ & $(0.9)$ & (23.4) \\
\hline \multirow[t]{2}{*}{6 months -1 year } & 1 & 7 & 3 & 1 & 4 & 10 & 26 \\
\hline & $(0.9)$ & (6.3) & (2.7) & $(0.9)$ & (3.6) & $(9.0)$ & (23.4) \\
\hline \multirow[t]{2}{*}{$>1-2$ years } & 0 & 4 & 0 & 6 & 2 & 7 & 19 \\
\hline & $(0.0)$ & (3.6) & $(0.0)$ & (5.4) & (1.8) & (6.3) & (17.1) \\
\hline \multirow[t]{2}{*}{$>2-3$ years } & 0 & 5 & 0 & 4 & 0 & 3 & 12 \\
\hline & $(0.0)$ & $(4.5)$ & $(0.0)$ & (3.6) & $(0.0)$ & (2.7) & (10.8) \\
\hline \multirow[t]{2}{*}{$>3-4$ years } & 0 & 0 & 0 & 1 & 0 & 0 & 1 \\
\hline & $(0.0)$ & $(0.0)$ & $(0.0)$ & $(0.9)$ & $(0.0)$ & $(0.0)$ & (0.9) \\
\hline \multirow[t]{2}{*}{$>4-5$ years } & 0 & 0 & 0 & 1 & 0 & 0 & 1 \\
\hline & $(0.0)$ & $(0.0)$ & $(0.0)$ & $(0.9)$ & $(0.0)$ & $(0.0)$ & (0.9) \\
\hline \multirow[t]{2}{*}{ No data } & \multirow{2}{*}{\multicolumn{2}{|c|}{$\begin{array}{c}17 \\
(15.4)\end{array}$}} & \multirow{2}{*}{\multicolumn{2}{|c|}{$\begin{array}{c}6 \\
(5.4)\end{array}$}} & \multirow{2}{*}{\multicolumn{2}{|c|}{$\begin{array}{c}3 \\
(2.7)\end{array}$}} & 26 \\
\hline & & & & & & & $(23.5)$ \\
\hline \multirow[t]{2}{*}{ Total } & \multirow{2}{*}{\multicolumn{2}{|c|}{$\begin{array}{c}40 \\
(36.1)\end{array}$}} & \multirow{2}{*}{\multicolumn{2}{|c|}{$\begin{array}{c}28 \\
(25.2)\end{array}$}} & \multirow{2}{*}{\multicolumn{2}{|c|}{$\begin{array}{c}43 \\
(38.7)\end{array}$}} & $111(100)$ \\
\hline & & & & & & & \\
\hline
\end{tabular}

Table 5. The summary distribution of ENL duration in MB leprosy patients at the Leprosy Division Dr. Soetomo General Academic Teaching Hospital Surabaya in 2015-2017

\begin{tabular}{lrrrr}
\hline \multirow{2}{*}{ Duration } & \multicolumn{3}{c}{ Year } & \multicolumn{1}{c}{ Total } \\
\cline { 2 - 4 } & \multicolumn{1}{c}{$2015(\%)$} & $2016(\%)$ & $2017(\%)$ & \multicolumn{1}{c}{ (\%) } \\
\hline$<6$ months & $6(5.4)$ & $6(5.4)$ & $14(12.6)$ & $26(23.4)$ \\
$\geq 6$ months & $17(15.3)$ & $16(14.4)$ & $26(23.5)$ & $59(55)$ \\
No data & $17(15.3)$ & $6(5.4)$ & $3(2.7)$ & $26(23.4)$ \\
\hline Total & $40(36)$ & $28(25.2)$ & $43(38.8)$ & $111(100)$ \\
\hline
\end{tabular}

Table 6. The summary distribution of ENL recurrences in MB leprosy patients at the Leprosy Division Dr. Soetomo General Academic Teaching Hospital Surabaya in 2015-2017

\begin{tabular}{lrrrrr}
\hline \multirow{2}{*}{ Duration } & \multicolumn{2}{c}{ Year } & \multicolumn{2}{c}{ Total (\%) } \\
\cline { 2 - 4 } & $2015(\%)$ & $2016(\%)$ & $2017(\%)$ & 34 \\
\hline Single & 7 & 8 & 19 & $(30.6)$ \\
& $(6.3)$ & $(7.2)$ & $(17.1)$ & 51 \\
Recurrent & 16 & 14 & 21 & $(46)$ \\
& $(14.4)$ & $(12.6)$ & $(18.9)$ & 26 \\
No data & 17 & 6 & 3 & $(23.4)$ \\
& $(15.3)$ & $(5.4)$ & $(2.7)$ & $111(100)$ \\
\hline Total & $40(36)$ & $28(25.2)$ & $43(38.8)$ & \\
\hline
\end{tabular}

Table 4, 5, and 6 showed the duration and recurrence of ENL in MB leprosy patients at the Leprosy Division of Dermatology and Venereology
Outpatient Department of Dr. Soetomo General Academic Teaching Hospital in 2015-2017. Information on the duration and recurrences of ENL 
showed that most ENL patients experienced reactions for more than 1 year (33 patients, 29.7\%). 59 patients suffered chronic reaction for $\geq 6$ months $(55 \%), 26$ patients suffered acute reactions for $<6$ months (23.4\%), and the longest reaction occurred for $>4$ years. Recurrences were found in 51 patients $(46 \%)$ and a single reaction in 34 patients (30.6\%). 26 ENL patients presented without duration and recurrence data.

\section{DISCUSSION}

This study described a relatively high prevalence of ENL, which was $28.8 \%$, among all leprosy patients and $33 \%$ of all the MB cases at the Leprosy division in 2015-2017. Four previous hospital-based systematic reviews reported a similar prevalence of ENL among MB cases ranging from $31 \%-37 \% .^{5}$ The total number of new patients who visited the Leprosy Division in 2015-2017 (mean: 128) decreased in comparison to 2010-2013 (mean: 148). ${ }^{6}$ A report by the World Health Organization (WHO) also showed a decrease in the number of new leprosy cases in Indonesia annually, which was 17,202 cases in 2015, 16,826 cases in 2016, and 15,910 cases in $2017 .{ }^{7}$ The decrease in the number of visits could be caused by a decrease in the number of new leprosy cases in Indonesia or due to the new National Health System which enforces vertical referrals based on the level of health services, from lower to higher facilities. Hence, leprosy cases are mostly managed by general practitioners at primary health care facilities. The prevalence of ENL continues to increase almost every year although there was a decrease in the number of visits. This was because patients with leprosy reactions are often referred to specialists in higher health care facilities like our tertiary hospital. In this study, a minimum observation period of 2 years from the data obtained in 2015-2017, including 1-year of MDT administration, and a minimum of 1 year period after RFT, were done to achieve more accurate information regarding the onset of ENL which often occurred within 1-3 years since MDT was given or after RFT. ${ }^{8,9}$

The results of this study indicated that the onset of ENL mostly occurred in the first year of MDT administration, as observed in 44 patients (39.6\%), followed by 41 patients $(36.9 \%)$ after RFT, and the latest onset was 4 years after MDT administration. This is consistent with other studies reporting that ENL more commonly occurs during MDT administration and RFT. Several studies found that ENL mostly occurred in the first year of MDT administration in 30 $45 \%$ of patients. ${ }^{8,10}$ Other studies showed that the majority of reactions occurred after RFT, which were in the second or third year since 12-month MDT treatment was given. ${ }^{9,11,12}$ Reactions often occurred after MDT administration, which could be caused by an increase in dead bacterial products that increased the total bacterial antigen and triggered an immune complex reaction to eliminate the antigen of the remaining $M$. lepra, which could induce ENL. ${ }^{13}$

The study findings showed that short-term observational studies were less effective because patients who had not experienced a reaction in the first year will be recorded as patients without ENL. Hence, studies with long-term observation time are best because leprosy is a chronic disease with long-term therapy, and leprosy reactions could occur late after RFT. These findings also emphasized the importance of knowledge about ENL onset to provide better monitoring and improve patient's compliance with treatment.

The results of duration and recurrences evaluation indicated that the majority of ENL patients experienced chronic reactions for $\geq 6$ months (59 patients) more than those who experienced acute reactions for $<6$ months (26 patients). Some data were not found (23 patients) due to the unknown onset of reactions in patients who had previous reactions (14 people), and patients who only visited once and had no follow up (12 people). The longest reaction lasted up to 4.5 years, and the time between the first and last episode averaged 13 months (1-55 months).

The durations were divided into acute $<6$ months and chronic $\geq 6$ months, while recurrent ENL was at least one further episode of ENL occurring 28 days or more after the withdrawal of treatment for ENL as defined by WHO. ${ }^{14}$ The findings in this study were similar to that of 11 years retrospective cohort study (1990-2000) with an average reaction time of 18 months. ${ }^{2}$ Long duration of reaction up to 5 years or even 8 years after MDT were also found. ${ }^{4,9}$ One of the factors associated with chronic ENL is age less than 35 years old and chronic ENL more than multiple acute ENL was found to be more severe and had a longer mean duration. ${ }^{2}$ The study result also showed that the majority of patients with ENL (51 patients, 46\%) experienced recurrences. This is following other studies that reported that most ENL patients experienced recurrences $(63 \%-64.4 \%))^{4,9}$

An interesting finding was a patient with a long duration of reaction that occurred for 4.5 years. It was a male patient aged 28 years old. He suffered from LL type leprosy with a chronic ENL characteristic, and he had a history of coinfection in the form of oral infections, namely periodontitis, in the first to second years with neglection and poor adherence during reaction treatment. The factors related to the long duration of ENL have not been widely studied other than age younger than 35 years and chronic ENL more 
than acute multiple ENL. ${ }^{2}$ Moreover, an infection can prolong the inflammatory state, and along with the patient's non-compliance behavior, the duration of reaction can be longer as well. These findings emphasized that monitoring and education for routine controls, especially in patients with chronic ENL, and early evaluation and treatment of focal or systemic infections are essential.

The result of epidemiological data evaluation in this study showed that the number of new MB leprosy patients in 2016 and 2017 decreased compared to 2015. However, the prevalence of patients with ENL continued to increase almost every year, especially in 2017 (32\% in $2015,32 \%$ in $2016,36 \%$ in 2017$)$. The evaluation of ENL onset in this study showed that ENL most often occurred during the first year of MDT, followed by after RFT, and the latest onset occurring 4 years after RFT. The majority of patients experienced chronic and recurrent reactions, with the longest reactions occurring up to 4.5 years (55 months).

Routine control during MDT, after RFT, and during the reaction treatment shall be affirmed in consideration of the onset of ENL occurrence as it can occur before, during, and after RFT. Close monitoring is required for ENL for chronic duration and those presenting with coinfection must be treated promptly. As ENL is often recurring, it shall be emphasized that there may be symptom-free intervals between recurrent episodes. Therefore, patients still need to be attentive in seeking treatment immediately in the event of a recurrence. Understanding about ENL chronic and recurrent nature is important to ensure patients' compliance and awareness to get a more comprehensive treatment.

\section{REFERENCES}

1. Salgado C, de Brito A, Salgado U, Spence J. Leprosy. In: Kang S, Amagai M, Bruckner A, Enk A, Margolis D, McMichael A, et al., editors. Fitzpatrick's Dermatology. New York: McGrawHill; 2019. p. 2892-924.

2. Pocaterra L, Jain S, Reddy R, Muzaffarullah S, Torres O, Suneetha S, et al. Clinical course of erythema nodosum leprosum: An 11-year cohort study in Hyderabad, India. Am J Trop Med Hyg 2006; 74(5): 868-79.

3. Walker SL, Lebas E, Doni SN, Lockwood DNJ,
Lambert SM. The Mortality Associated with Erythema Nodosum Leprosum in Ethiopia: A Retrospective Hospital-Based Study. PLoS Negl Trop Dis 2014; 8(3): 1-6.

4. Kumar B, Dogra S, Kaur I. Epidemiological Characteristics of Leprosy Reactions: 15 Years Experience from North India. Int J Lepr 2004; 72(2): 123-33.

5. Voorend CGN, Post EB. A Systematic Review on the Epidemiological Data of Erythema Nodosum Leprosum, a Type 2 Leprosy Reaction. PLoS Negl Trop Dis 2013; 7(10): 1-10.

6. Pratamasari M., Listiawan MY. Retrospective Study: Type 1 Leprosy Reaction. BIKKK - Berk Ilmu Kesehat Kulit dan Kelamin - Period Dermatology Venereol 2015; 27: 137-43.

7. World Health Organization. Weekly epidemiological record. Wkly Epidemiol Rec 2019; 94(35/36): 389-412.

8. Feuth M, Brandsma JW, Faber WR, Bhattarai B, Feuth T, Anderson AM. Erythema nodosum leprosum in Nepal: A retrospective study of clinical features and response to treatment with prednisolone or thalidomide. Lepr Rev 2008; 79(3): 254-69.

9. Saunderson P, Gebre S, Byass P. ENL reactions in the multibacillary cases of the AMFES cohort in central Ethiopia: Incidence and risk factors. Lepr Rev 2000; 71(3): 318-24.

10. Manandhar R, LeMaster JW, Roche PW. Risk factors for erythema nodosum leprosum. Int J Lepr Other Mycobact Dis 1999; 67(3): 270-8.

11. Listiyawati I, Sawitri, Agusni I, Prakoeswa C. Terapi Kortikosteroid Oral pada Pasien Baru Kusta dengan Reaksi Tipe 2. 2015; 48-54.

12. Balagon MVF, Gelber RH, Abalos RM, Cellona R $\mathrm{V}$. Reactions following completion of 1 and 2 year multidrug therapy (MDT). Am J Trop Med Hyg 2010; 83(3): 637-44.

13. NLEP National Leprosy Eradication Program. Pathogenesis of Leprosy. In: Training Manual for Medical Officers. Nirman Bhawan, New Delhi: Directorate General of Health Services Ministry of Health \& Family Welface; 2009. p. 11-4.

14. World Health Organization W. Weekly Epidemiological Record. 2017; 92(35): 501-19. 